\title{
Implantable Subacromial Balloon Spacers in Patients With Massive Irreparable Rotator Cuff Tears: A Systematic Review of Clinical, Biomechanical, and Financial Implications
}

\author{
William L. Johns, B.S., Nikhil Ailaney, B.S., Kevin Lacy, B.S., Gregory J. Golladay, M.D., \\ Jennifer Vanderbeck, M.D., and Niraj V. Kalore, M.D.
}

Purpose: To determine the clinical, biomechanical, and financial impact of the use of subacromial balloon spacers in the surgical management of massive, irreparable rotator cuff tears (RCTs). Methods: All studies assessing the use of implantable subacromial balloon spacers for management of massive, irreparable RCTs were systematically searched. Risk of bias was assessed using Methodological Index for Non-Randomized Studies criteria. Data extraction and analysis was performed for pain and function scores, shoulder range of motion (ROM), glenohumeral contact pressure and vertical migration of humeral head, and cost. Subjective synthesis was performed with forest plots when outcomes were reported in 3 or more studies. Results: In total, 19 studies met inclusion criteria for analysis; 337 patients (mean age 68 years) had 343 subacromial balloon spacer implantations. Throughout a mean follow-up of 33 months, there was significant improvement in the Total Constant Score (preoperative: 22.5-41.8; postoperative: 51.4-72.3), Oxford Shoulder Score (preoperative: 21.3-26; postoperative: 34.39-48.2), American Shoulder and Elbow Surgeons score (preoperative: 24.5-59.1; postoperative: 72.5-85.7), and shoulder ROM parameters. Subacromial balloon spacer placement resisted superior humeral head migration (range of preoperative to postoperative difference: 2.8-6.2 $\mathrm{mm}$ ) and decreased peak subacromial pressure during shoulder ROM. Conclusions: Existing literature of subacromial balloon spacers has a high risk of bias, lack of appropriate control, and low levels of evidence. A qualitative synthesis indicates that subacromial balloon spacer implantation in patients with massive irreparable RCTs is cost-effective and leads to improved function (Total Constant Score and Oxford Shoulder Score) and ROM. In cadaveric studies, subacromial balloon spacers resist superior humeral head migration and reduce subacromial pressure. The theoretical risk of biodegradation of the balloon spacer has not been substantiated in study of up to 5-years follow-up, and the risk of complications from this procedure appears to be minimal. Level of Evidence: IV; Systematic review of level III-IV studies.

$\mathbf{R}$ otator cuff tears are found in nearly $50 \%$ of patients aged $70-90$ years. ${ }^{1,2}$ Among these rotator cuff tears, up to $40 \%$ of all tears are categorized as massive, ${ }^{3,4}$ which is defined as the rupture of 2 or more rotator cuff tendons and/or retraction $\geq 5 \mathrm{~cm}$ away

From the School of Medicine (W.L.J., N.A., K.L.) and Department of Orthopaedic Surgery (G.J.G., J.V., N.V.K.), Virginia Commonwealth University Health, Richmond, Virginia, USA.

W.J. and N.A. contributed equally to this work.

The authors report the following potential conflicts of interest or sources of funding: G.J.G. reports financial support from OrthoSensor (consultant, stock, paid presentations), KCI (research support), Cerus (research support), Arthroplasty Today (deputy editor, stipend), and is a member of the editorial board of the Journal of Arthroplasty. N.V.K. reports American Association of Hip and Knee Surgeons (board or committee member), Arthroscopy (editorial or governing board), Arthroscopy Association of North America (board or committee member), Hip International (editorial or from the tendon insertion site. ${ }^{5,6}$ A key issue for these massive rotator cuff tears is that many are irreparable, due to significant tendon retraction to the glenoid, ${ }^{7,8}$ the tear being $\geq 3 \mathrm{~cm}$ in size, ${ }^{7}$ extensive muscle atrophy, ${ }^{7,8}$ or a combination of these factors.

\footnotetext{
governing board). Full ICMJE author disclosure forms are available for this article online, as supplementary material.

Received February 21, 2020; accepted June 21, 2020.

Address correspondence to William L. Johns, B.S., Virginia Commonwealth University School of Medicine, 1212 N 27th St., Richmond, VA 23298. E-mail:e.johnswl@vcu.edu

(C) 2020 THE AUTHORS. Published by Elsevier Inc. on behalf of the Arthroscopy Association of North America. This is an open access article under the CC BY-NC-ND license (http://creativecommons.org/licenses/by-nc-nd/4.0/). 2666-061X/20265

https://doi.org/10.1016/j.asmr.2020.06.011
} 
Despite the many surgical options that exist, ${ }^{9-23}$ there continues to be no consensus on the appropriate surgical strategy for patients suffering from massive, irreparable rotator cuff tears. A potential treatment for massive, irreparable rotator cuff tears is the InSpace arthroscopic biodegradable balloon spacer (InSpace Balloon; Orthospace, Caesarea, Israel). This spacer is placed within the subacromial space via arthroscopic delivery and inflated with saline. ${ }^{24}$ The biodegradable spacer is composed of a copolymer material that lasts for approximately 12 months before full degradation occurs. ${ }^{24}$ Reported advantages of this device are its minimal technical demands and shorter operative duration, ${ }^{7,24,25}$ evidence of expedited postoperative shoulder mobility, ${ }^{26}$ and improved postoperative clinical function scores, such as Total Constant Score (TCS), American Shoulder and Elbow Surgeons (ASES) score, and Oxford Shoulder Score (OSS) in patients, ${ }^{27-29}$ and the ability to implant the device under fluoroscopic guidance without general anesthesia in those patients with medical contraindications. ${ }^{7,25}$ Recent systematic reviews by Moon et al. ${ }^{29}$ and Stewart et al. ${ }^{30}$ demonstrated improvements in patient satisfaction and clinical outcomes such as TCS and ASES in patients managed with subacromial balloon spacers. However, there is limited research regarding the potential biomechanical and clinical advantages in addition to the cost associated with subacromial balloon spacers in a systematic review. Further understanding of the biomechanical and financial literature regarding subacromial balloon spacers is imperative; therefore, review and analysis of these outcomes in the present study provides value to the existing systematic reviews on the topic.

Therefore, the purpose of this systematic review is to determine the clinical, biomechanical, and financial impact of the use of subacromial balloon spacers in the surgical management of massive, irreparable rotator cuff tears. We hypothesized that the use of implantable subacromial balloon spacers in patients with massive, irreparable rotator cuff tears would be associated with improved shoulder range of motion (ROM) and clinical function scores such as TCS, ASES, and OSS in addition to biomechanical advantages such as increased acromiohumeral distance and decreased subacromial pressure, all in a cost-effective manner.

\section{Methods}

The study was designed in accordance with the Preferred Reporting Items for Systematic Reviews and Meta-Analyses protocol $^{31}$ using Cochrane Review Methods. $^{32}$

\section{Search Strategy}

MEDLINE, EMBASE, CINAHL, and the Cochrane Library were searched from their inception to September 2019. The search strategy (Table 1) was developed with the assistance of a medical librarian. Following
Table 1. MEDLINE Search Strategy

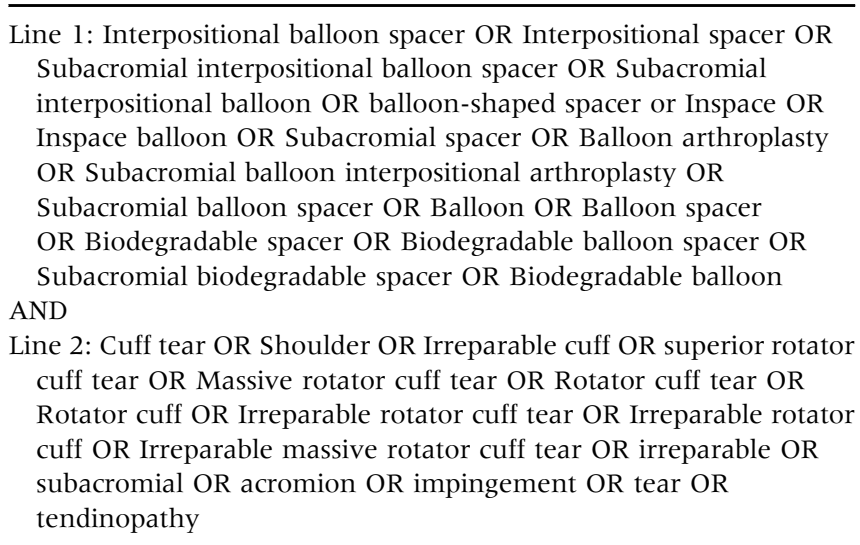

identification of potential articles for inclusion, an initial screening of titles and abstracts that addressed the research question of interest was then performed. Afterwards, relevant full-text articles were obtained and re-evaluated for eligibility based on the inclusion and exclusion criteria below to determine the final studies to be included in the systematic review. Any disagreements regarding the articles for inclusion were resolved by the senior author. The bibliographies of all articles identified also were searched for further studies that specifically pertained to cost, biomechanical, and clinical outcomes involving the use of subacromial balloon spacers for the management of massive, irreparable rotator cuff tears. The authors determined that inclusion of nonrandomized studies was appropriate considering that randomized controlled trials on the topic have not yet been completed, and therefore this is the only literature available that effectively describes the topic.

\section{Inclusion and/or Exclusion Criteria}

This article includes English-language original data studies published at any time that report outcomes relating to biomechanics, clinical function scores (TCS, ASES, OSS, University of California Los Angeles [UCLA] Shoulder Score, visual analog scale [VAS]), shoulder ROM, patient satisfaction, costs, and complications following the use of subacromial balloon spacers for the management of massive, irreparable rotator cuff tears. Studies that were excluded were those not written in English and those did not assess biomechanical, clinical, or financial outcomes after the use of subacromial balloon spacers in massive, irreparable rotator cuff tears.

\section{Quality Appraisal and Assessment of Risk of Bias}

The quality and assessment of risk of bias for each clinical study included in the review was independently rated by the primary and senior authors using the Methodological Index for Non-Randomized Studies (MINORS) criteria, which is a validated 8-item checklist that is designed to analyze the quality of comparative 
Fig 1. Search strategy and study selection process using Preferred Reporting Items for Systematic Reviews and Meta-Analyses methodology.
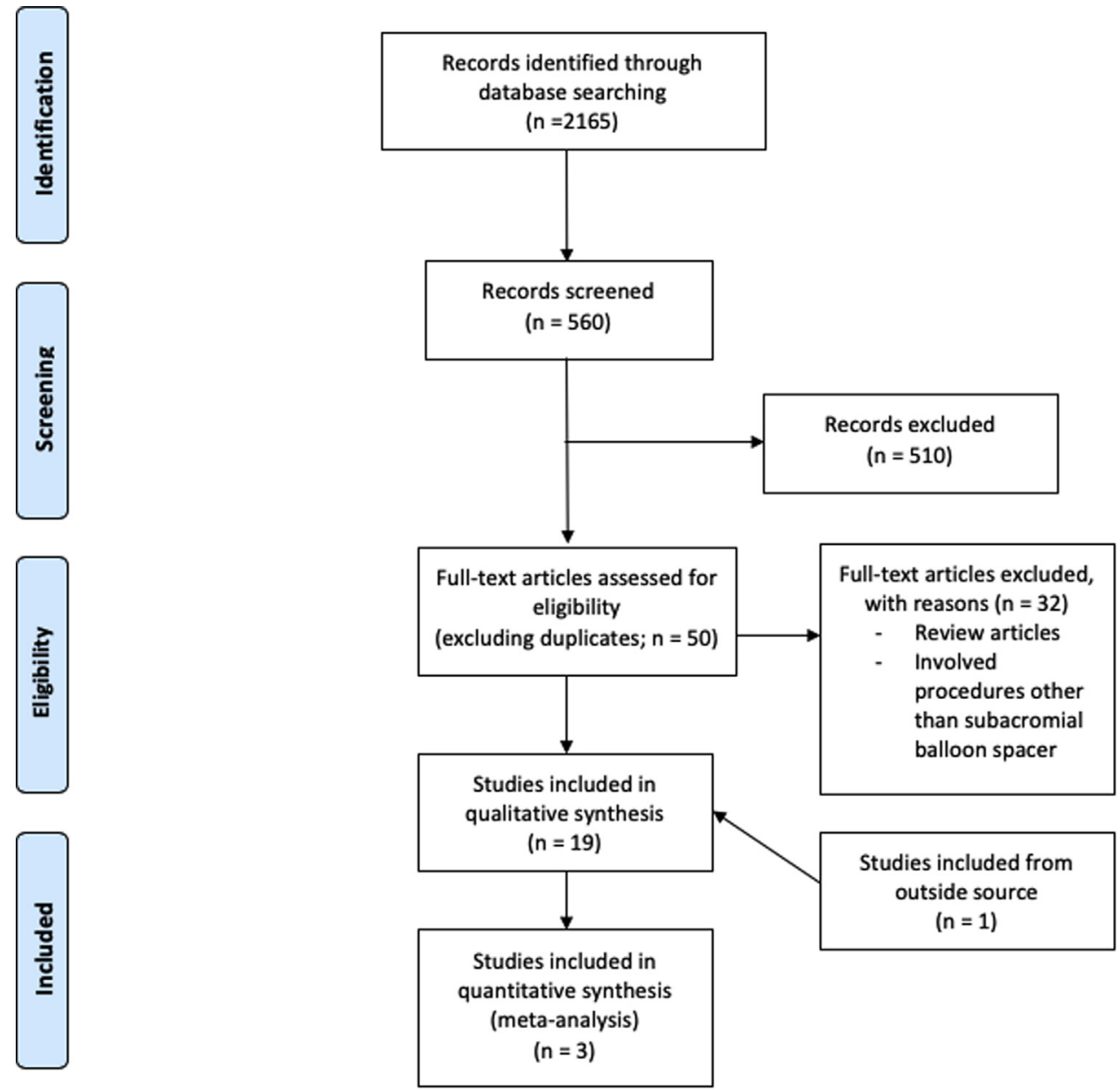

and noncomparative nonrandomized, surgical studies. ${ }^{33}$ Each checklist item is scored from 0 to 2, in which a score of 0 is assigned if an item is not reported, a score of 1 is assigned if an item is only partially addressed, and a score of 2 is provided if the item parameter is completely addressed. Follow-up of 18 months was considered adequate to assess clinical efficacy and potential complications of the subacromial balloon spacer as device degradation is reportedly complete within 12 months of insertion. ${ }^{24,30}$ The Cohen's $\kappa$ statistic was calculated to determine interrater reliability. ${ }^{34}$ Cohen suggested that the kappa value should be interpreted as follows: values $<0$ represents less than chance agreement, 0.01-0.20 represents slight agreement, 0.21-0.40 represents fair agreement, 0.41-0.60 represents moderate agreement, 0.61-0.80 represents substantial agreement, and 0.81-1.00 represents almost-perfect agreement. ${ }^{35,36}$

\section{Data Collection and Abstraction}

Two investigators independently extracted data from those groups with massive, irreparable rotator cuff tears treated with subacromial balloon spacer from all eligible studies. Any disagreements were resolved by discussion. Unresolved disagreements were resolved by the senior author. The following data was extracted for the clinical and biomechanical studies: first author, year of publication, journal publication, sample size, individual group demographics, surgical interventions, mean follow-up, and the primary and secondary outcomes. The primary outcome measures for the clinical studies were TCS, OSS, ASES score, VAS pain score; shoulder ROM parameters such as abduction, flexion, and external rotation; and radiologic measures such as acromiohumeral distance, proximal humeral migration. The primary outcome measures for the biomechanical studies were mean and peak subacromial pressure, glenohumeral contact pressure, functional abduction force, acromiohumeral distance, inferior-superior humeral head migration, and anterior-posterior humeral head migration. Secondary outcomes included resource use (financial cost, qualityadjusted life years [QALYs], operating room time, anesthesia requirements, hospital length of stay), patient satisfaction data, and complications. 


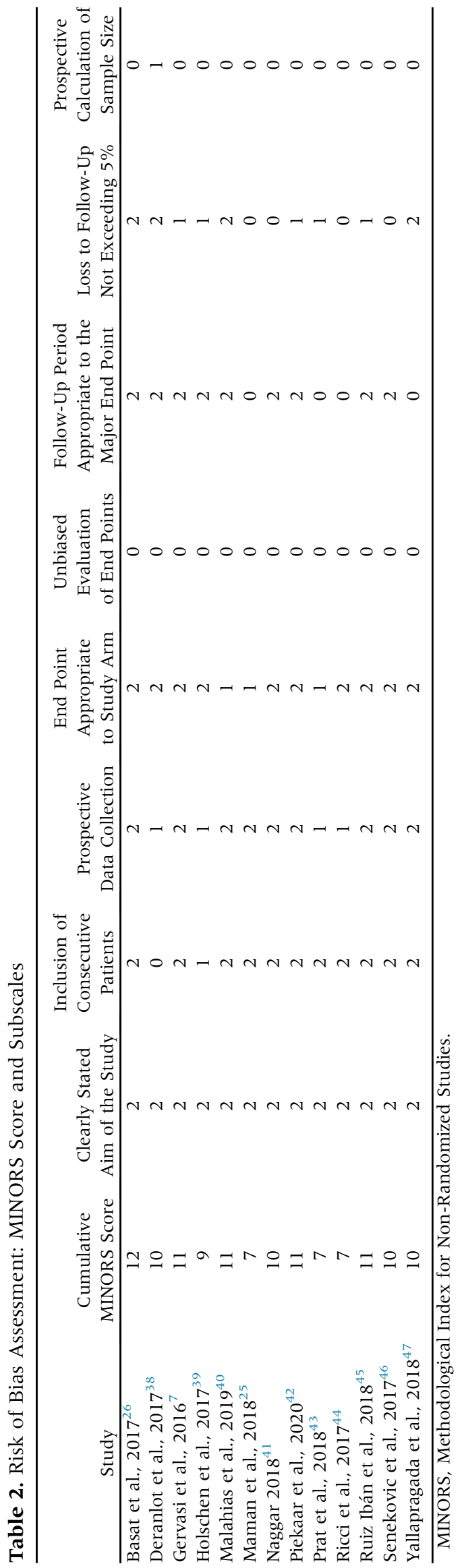

\section{Meta-Analysis Methodology for Biomechanical Studies}

Meta-analysis with the random-effects model was performed for biomechanical studies when sufficient data existed from 2 or more studies. Data analysis was done using the Review Manager (RevMan) version 5.3. The Cochrane Collaboration, 2014. Standardized mean difference with $95 \%$ confidence interval was calculated for continuous data and statistical significance was determined by using $P$ values, with alpha set at .05 . Heterogeneity was assessed by the Breslow-Day method ${ }^{37}$ using the $\chi^{2}$ test and $\mathrm{I}^{2}$ statistic. Meta-analysis was not performed for clinical studies because of the heterogeneity and potential for high risk of bias among studies.

\section{Results}

\section{Search Results}

The search returned a total of 2165 articles. After duplicates were excluded and the title and abstract screen was performed, 50 articles were retrieved for full-text screening. A total of 18 articles met the aforementioned inclusion criteria. One additional article was retrieved from an outside source. Among the 19 total articles that met inclusion criteria, 4 articles reported biomechanical outcomes, 14 articles reported clinical outcomes, and 1 article reported financial outcomes regarding the use of subacromial balloon spacers for the management of irreparable rotator cuff tears. The process of study selection is included in Figure 1. Risk of bias assessment using the MINORS criteria is displayed in Table $2^{38-47}$ and Figure 2, and design characteristics of selected studies are included in Tables 3 and $4 .{ }^{38-47}$ Two studies by Piekaar et al. ${ }^{1,42}$ were retrieved, which included clinical results from the same group at 1 and 3 years of follow-up after implantation of a subacromial balloon spacer. Only the results from Piekaar et al. ${ }^{42}$ reporting 3-year follow-up were included in the results and statistical analysis of the present study.

\section{Quality Appraisal and Risk of Bias}

A total of 13 nonrandomized, clinical studies were assessed using MINORS criteria. There was not an appropriate comparison group in the included studies, so the 8-item MINORS criteria for noncomparative studies were used (Table 2). ${ }^{38-47}$ The mean MINORS score was 9.69. The $\kappa$ statistic value for interrater reliability was 0.81 , suggesting strong agreement between raters.

\section{Patient Demographics}

The 19 studies that met inclusion criteria involved a total of 337 patients, with a total of 343 subacromial balloon spacer surgeries performed (300 included in clinical studies, 43 included in biomechanical studies). Mean reported age of subjects in both clinical and 


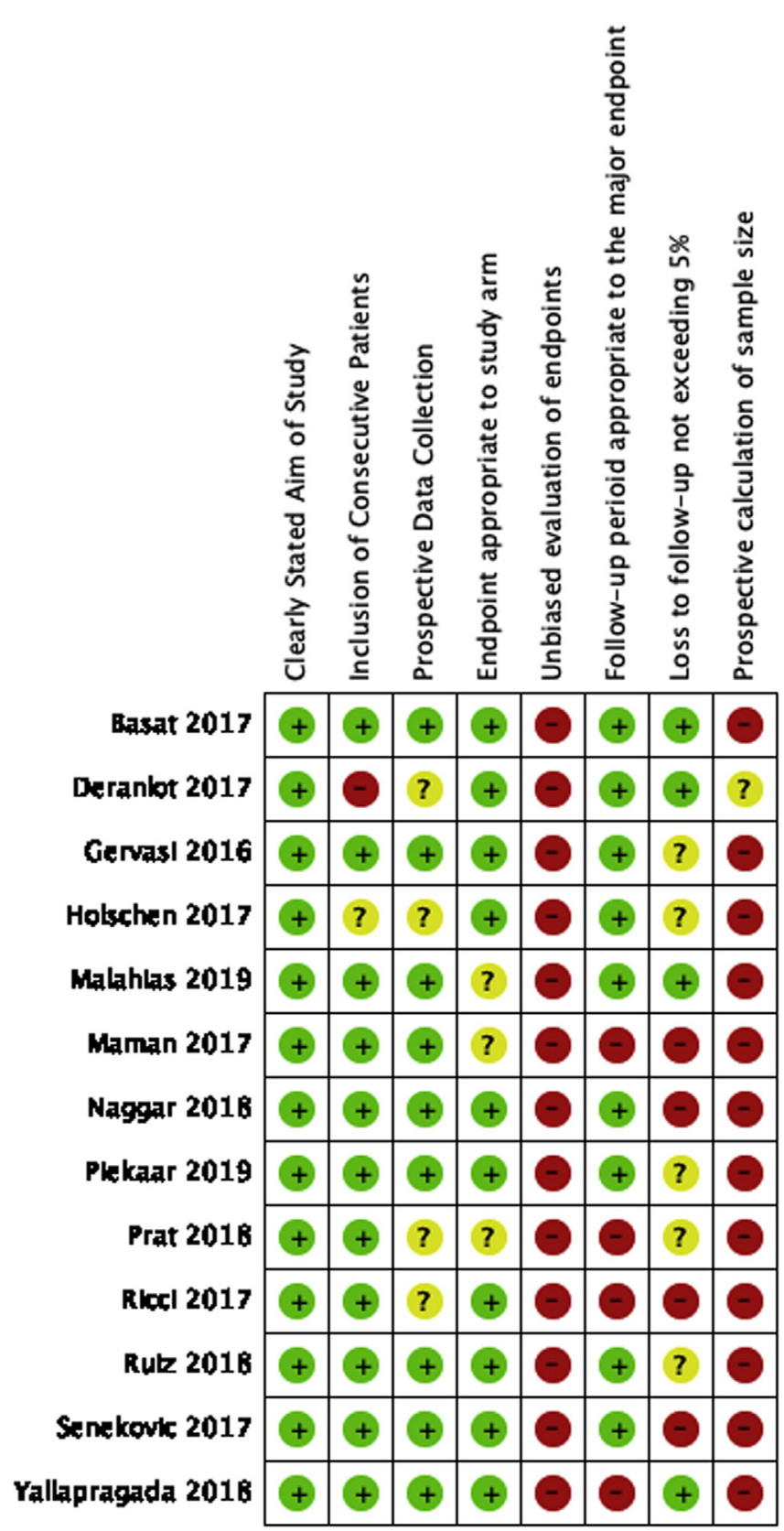

Fig 2. Risk of bias summary: review authors' judgments about each risk of bias item for each included study. Green $=$ low risk of bias, yellow $=$ unclear risk of bias, red $=$ high risk of bias.

biomechanical studies was 68 years old. In total, 158 of reported patients were male and 143 were female; however, not all of the biomechanical studies reported patient sex. All studies included patients with persistent symptoms for a minimum of 3 to 6 months with failure of conservative treatment, including activity modification, treatment with non-steroidal anti-inflammatory medications, intra-articular corticosteroid injections, and/or physical therapy before balloon spacer treatment. Among the studies that reported preoperative characteristics, 75 of $76(98.6 \%)$ of patients had a preoperative Patte classification of 3. In addition, 101 of $125(80.8 \%)$ of the included patients had a preoperative Goutallier classification of $\geq 3$ and 24 of 125 $(19.2 \%)$ had a preoperative classification of $\leq 2$. Patients with extensive glenohumeral osteoarthritis, known allergy to balloon spacer material, or active infection were excluded from operative intervention in all included studies. Two studies included patients with previous attempts at surgical management. ${ }^{7,42}$ The study by Gervasi et al. $^{7}$ included 5 of $15(33 \%)$ of patients who previously were treated with either rotator cuff repair or subacromial debridement and biceps tenotomy before subacromial balloon spacer placement. In all clinical studies, the patient was indicated for arthroscopic shoulder surgery preoperatively based on clinical symptoms and/or magnetic resonance imaging (MRI) findings (Table 5), ${ }^{38-47}$ and 8 of 13 clinical studies specifically reported that the rotator cuff tear was deemed irreparable intraoperatively by the primary surgeon based on the inability to attach the tendon to its insertion footprint. ${ }^{26,38,40,42,44-47}$ Among the clinical studies, a total of 95 biceps tenotomy procedures were reported and performed in concordance with the balloon spacer placement procedure and an additional 4 studies included biceps tenotomy but did not report the prevalence. A total of 33 partial rotator cuff repairs were performed in conjunction with implantation of a subacromial balloon spacer. Average length of followup in studies reporting clinical outcomes was 33.37 months. Baseline demographic data for patients included in each study is included in Table 5. ${ }^{38-47}$

\section{Functional Scores}

Patients treated with a subacromial balloon spacer demonstrated overall improvement in postoperative TCS compared with preoperative TCS based on the data from 11 studies (preoperative range: 22.5-41.8; postoperative range: 51.4-72.3; Fig 3). Of these studies, TCS outcomes were reported in a combined 19 follow-up periods from 12 months to 60 months postoperatively. All of these studies reported statistically significant improvement in TCS from preoperative to postoperative measurements at all short-term and long-term follow-up timepoints (Fig 4). There was also substantial improvement from pre- to postoperative OSS after the subacromial balloon spacer procedure according to the data from 3 studies (preoperative range: 21.3-26; postoperative range: 34.39-48.2; Fig 5). In addition, 4 studies reporting ASES scores showed significant improvement from preoperative to postoperative values (Fig 6). In terms of VAS pain scores, Ricci et al. $^{44}$ found significant improvement in VAS scores in those groups with $3-(6.13-3.38, P=.0005)$, 6- $(6.45-3.67, P=.0019), 12-(6.25-2.86, P=.0001)$, and 24-month (6.6-2.8, $P=.0019)$ follow-up. Gervasi et al. ${ }^{7}$ demonstrated similar findings at 12-month (7.1-1.4, $P<.0001)$ and 24-month (7.1-2.1, $P<.0001)$ follow-up. 


\begin{tabular}{cccc} 
Study & LOE & n & Adjustment for Confounding Variables \\
\hline Basat et al., $2017^{26}$ & P (IV) & 12 & Inclusion: MIRCT (Patte $>$ stage 3,
\end{tabular}

$\mathrm{P}(\mathrm{IV})$

12

Inclusi

Goutallier state 3 or 4 , acromiohumeral

distance $<7 \mathrm{~mm}$ ), complete disruption of supraspinatus and infraspinatus, presence of functional deltoid, age $>60 \mathrm{y}$, failure of conservative treatment $>6$ mo. Exclusion: rotator cuff arthropathy, repairable RCT during MRI or arthroscopy, shoulder

infection, neurologic deficit in shoulder muscles

Deranlot et al., $2017^{38} \quad$ R (IV)

Gervasi et al., 2016

P (IV)

15

Holschen et al., $2017^{39}$
R (III)
39

\section{Inclusion: MIRCT (Patte $>$ stage 2 ,}

Goutallier $>$ or $=$ stage 3, no OA), Ffailure

of conservative treatment $>6 \mathrm{mo}$

minimum 1-year f/u. Exclusion: CTA >

stage 3 Hamada class, subscapularis tear

intraoperative ability to repair tendon.

Statistical analysis: CA was adjusted for

age and sex, subgroup analysis (post hoc)

was performed to identify differences

based on the status of the long head biceps

tendon (spontaneous preoperative

rupture of biceps tendon didn't influence

postop acromiohumeral distance or

constant score)

Inclusion: MIRCT, age $>50 \mathrm{y}$, failure of conservative therapy $>4$ mo. Exclusion: significant OA, GH instability, major joint trauma, infection, necrosis in shoulder.

Statistical analysis: Adjusted CS and their subscales were determined using a

repeated measures analysis variance model

Inclusion: MRCT, painful loss of shoulder

function. Exclusion: no arthritis, no

cranial migration of humeral head $>$ type

II Hamada, cuff tear arthropathy

Experimental Group(s) Interventions

Control Group

Interven

Balloon spacer placement, subacromial

debridement $+/$ - biceps tenotomy (if

biceps tendon intact)

Balloon spacer placement, Subacromia debridement $+/$ - biceps tenotomy (if biceps tendon intact)

Fluoroscopic-guided balloon spacer placement

Balloon spacer placement with subacromial debridement or partial repair $+/$ - biceps tenotomy (if biceps tendon intact)
RTC debridement, synovectomy, bursectomy, biceps tenotomy/ tenodesis, and partial

reconstruction/repair of rotator cuff if possible 


\begin{tabular}{|c|c|c|c|}
\hline Study & LOE & $\mathrm{n}$ & Adjustment for Confounding Variables \\
\hline Ricci et al., $2017^{44}$ & $\mathrm{R}(\mathrm{IV})$ & 30 & $\begin{array}{l}\text { Inclusion: Goutallier stage } 3 \text { or } 4 \text {, Persistent } \\
\text { pain for }>6 \text { mo, failure of conservative } \\
\text { treatment. Exclusion: GH OA, GH } \\
\text { instability, previous shoulder surgery, } \\
\text { shoulder infection }\end{array}$ \\
\hline Ruiz Ibán et al., $2018^{45}$ & $\mathrm{P}(\mathrm{IV})$ & 15 & $\begin{array}{l}\text { Inclusion: MIRCTs on MRI, }>50 \text { y old, } \\
\text { persistent pain/disability for }>6 \text { mo w/ }>3 \\
\text { mo failed conservative therapy, Goutallier } \\
\text { stages } 3 \text { or } 4 \text {, Irreparability confirmed on } \\
\text { arthroscopy, No cuff tear arthropathy, No } \\
\text { GH OA. Statistical analysis: Post hoc } \\
\text { analysis performed between preoperative } \\
\text { situation (age, degenerative arthropathy, } \\
\text { Constant score, active or passive ROM, } \\
\text { pseudoparalysis) of the } 6 \text { subjects that had } \\
\text { clinically relevant improvement and the } 9 \\
\text { subjects that did not fare well }\end{array}$ \\
\hline Senekovic et al., $2017^{46}$ & $\mathrm{P}(\mathrm{IV})$ & 24 & Inclusion: persistent pain/functional \\
\hline
\end{tabular}

Inclusion: persistent pain/functional
disability $>6 \mathrm{mo}$, imaging confirmation of

$\mathrm{RCT}$, failure of conservative therapy,

confirmation of irreparability and fatty

infiltration on arthroscopy. Exclusion: GH

OA, GH instability, active shoulder

infection, previous shoulder surgery, DM,

immunosuppression, coagulopathy.

Statistical analysis: adjusted CS and its

subscales were determined using a

repeated measures analysis variance

model (subgroup analysis revealed there

were no statistical differences between

clinical outcomes of subjects who went

device implantation alone vs those who

had any level of tendon repair, but those

patients who had repair were NOT

included in clinical efficacy assessment

results).

Inclusion: MIRCT, failed conservative management $>6 \mathrm{mo}$, muscle retraction

(Patte > stage 2), muscle atrophy, fatty

infiltration (Goutallier stage 3). Exclusion:

GH OA Hamada grade 3, no preserved

passive ROM, active infection, or allergies

to the balloon material
Experimental Group(s) Interventions

Control Group

Balloon spacer placement, subacromia

bursectomy, biceps tenotomy,

acromioplasty

Balloon spacer placement, subacromial debridement $+/$ - biceps tenotomy (if

biceps tendon intact)

Balloon spacer placement $+/$ - biceps

tenotomy, partial repair was

performed in 3 patients

Balloon spacer placement, subacromial debridement, biceps tenotomy in 9 patients 
Table 4. Design Characteristics of Each Clinical Study Included in this Systematic Review: Part 2

\begin{tabular}{|c|c|c|c|c|}
\hline Study & Measured Outcomes & $\begin{array}{l}\text { Mean Follow-Up } \\
\text { (Months } \pm \text { SD) }\end{array}$ & $\begin{array}{l}\text { Patients Lost } \\
\text { to Follow-Up }\end{array}$ & Conclusions \\
\hline Basat et al., $2017^{26}$ & $\begin{array}{l}\text { Constant score; Oxford } \\
\text { Shoulder Score; VAS; } \\
\text { abduction }\end{array}$ & $38.3 \pm 8.03$ & - & $\begin{array}{l}\text { In patients in whom conservative treatment is } \\
\text { insufficient for irreparable RTC tears, the } \\
\text { biodegradable balloon has shown to improve } \\
\text { mean constant score, mean Oxford Shoulder } \\
\text { Score, and mean shoulder abduction degree. }\end{array}$ \\
\hline Deranlot et al., $2017^{38}$ & $\begin{array}{l}\text { Flexion, abduction, external } \\
\text { rotation; Constant score; } \\
\text { acromiohumeral distance; } \\
\text { Hamada classification }\end{array}$ & $32.8 \pm 12.4$ & - & $\begin{array}{l}\text { Arthroscopic implantation of a subacromial spacer } \\
\text { for irreparable RTC tears leads to significant } \\
\text { improvement in mean Constant score and } \\
\text { shoulder anterior elevation, abduction, and } \\
\text { external rotation at a minimum of } 1 \text { year } \\
\text { postoperatively. }\end{array}$ \\
\hline Gervasi et al., $2016^{7}$ & $\begin{array}{l}\text { Constant score; ASES score, } \\
\text { range of motion }\end{array}$ & 24 & $\begin{array}{l}1 / 15(6.66 \%) \text { patients lost to follow-up at } 6 \text { months } \\
\text { due to ref for RTSA (clinical condition not } \\
\text { improving) and only } 10 / 15 \text { patients completed at } \\
\text { least } 2 \text { years' follow-up }\end{array}$ & $\begin{array}{l}\text { Fluoroscopy-guided implantation of the InSpace } \\
\text { system for management of MRTC tears results in } \\
\text { an overall improvement in total Constant score } \\
\text { and ASES score beginning at } 6 \mathrm{wk} \\
\text { postoperatively and sustained by at least } 12 \mathrm{wk} \\
\text { postoperatively. }\end{array}$ \\
\hline Holschen et al., $2017^{39}$ & $\begin{array}{l}\text { Constant score, ASES score, } \\
\text { subjective satisfaction }\end{array}$ & $\begin{array}{l}30.6 \text { for Group A, } \\
22.3 \text { for Group B }\end{array}$ & $\begin{array}{l}2 / 23(8.70 \%) \text { patients lost to follow-up because of } \\
\text { conversion to reverse total shoulder arthroplasty } \\
\text { due to lack of improvement of symptoms }\end{array}$ & $\begin{array}{l}\text { The ISB is a feasible treatment for patients with } \\
\text { MRCT and compared to conventional treatment } \\
\text { methods, the ISB results in greater absolute } \\
\text { improvement in both ASES score and Constant } \\
\text { score. }\end{array}$ \\
\hline Malahias et al., $2019^{40}$ & $\begin{array}{l}\text { Constant score, ASES score, } \\
\text { Flexion, abduction, external } \\
\text { rotation, internal rotation, } \\
\text { VAS score, patient } \\
\text { satisfaction }\end{array}$ & $22.1 \pm 9.8$ & 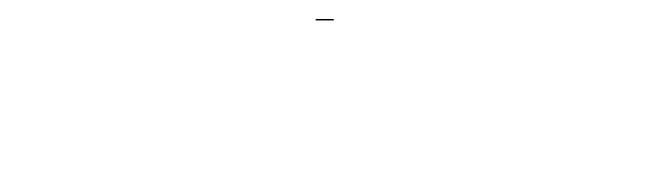 & $\begin{array}{l}\text { The use of ISB for patients suffering from MRCT } \\
\text { leads to significantly improved ASES score, } \\
\text { Constant score, and VAS pain scores. The use of } \\
\text { arthroscopic partial repair with ISB was not } \\
\text { superior to ISB implantation alone. }\end{array}$ \\
\hline Maman et al., $2018^{25}$ & Constant score & 12 & $\begin{array}{l}\text { Only } 43 \%(18 / 42) \text { of patients were willing to } \\
\text { return between } 24-40 \text { months postoperatively } \\
\text { either due to logistical reasons or other non- } \\
\text { shoulder comorbidities }\end{array}$ & $\begin{array}{l}\text { Spacer implantation in patients with MRTC } \\
\text { provides significant improvement in Constant } \\
\text { score up to the 1-y follow-up visit. Additional } \\
\text { long head of the biceps tenotomy did not } \\
\text { influence the postoperative results. }\end{array}$ \\
\hline Naggar $2018^{41}$ & Constant score, UCLA & 52.5 & - & $\begin{array}{l}\text { Arthroscopic implantation of an inflatable } \\
\text { biodegradable balloon provides significant } \\
\text { improvement in Constant score and UCLA score } \\
\text { in patients with MIRCT. }\end{array}$ \\
\hline Piekaar et al., $2020^{42}$ & $\begin{array}{l}\text { NRS for pain, Oxford Shoulder } \\
\text { Score, Constant-Murley } \\
\text { shoulder score (CMS), } \\
\text { Satisfaction }\end{array}$ & 34 & $\begin{array}{l}1 \text { patient lost to follow-up due to chemotherapy, } \\
1 \text { patient died } 2 \text { mo postoperatively from cardiac } \\
\text { disease, } 2 \text { patients with RTSA, and } 1 \text { patient } \\
\text { received repeat arthroscopy }\end{array}$ & $\begin{array}{l}\text { Arthroscopic implantation of the balloon spacer } \\
\text { leads to sustained reduction in NRS pain score } \\
\text { and Oxford Shoulder Score in patients with } \\
\text { irreparable RTC tears during } 3 \text { years of } \\
\text { follow-up. }\end{array}$ \\
\hline
\end{tabular}




\begin{tabular}{|c|c|c|c|c|}
\hline Study & Measured Outcomes & $\begin{array}{l}\text { Mean Follow-Up } \\
(\text { Months } \pm \text { SD })\end{array}$ & $\begin{array}{l}\text { Patients Lost } \\
\text { to Follow-Up }\end{array}$ & Conclusions \\
\hline Prat et al., $2018^{43}$ & $\begin{array}{l}\text { UCLA, Quick-DASH; flexion, } \\
\text { external rotation, internal } \\
\text { rotation, satisfaction, } \\
\text { upward migration index } \\
\text { (UMI) }\end{array}$ & $14.4 \pm 15$ & \multirow[t]{2}{*}{$\begin{array}{l}2 \text { patients lost to follow-up } 3 \text { mo after surgery } \\
(7.69 \%)\end{array}$} & $\begin{array}{l}\text { Subacromial balloon spacer placement for MIRCT } \\
\text { led to improvements in UCLA score, but poor } \\
\text { patient satisfaction rating and minimal } \\
\text { improvement in proximal humeral head } \\
\text { migration on postoperative radiographs. }\end{array}$ \\
\hline Ricci et al., $2017^{44}$ & $\begin{array}{l}\text { Constant score, VAS score, } \\
\text { subacromial space on AP } \\
\text { radiographs }\end{array}$ & 9.8 & & $\begin{array}{l}\text { Placement of subacromial spacer resulted in } \\
\text { sustained improvement in TCS, range of motion, } \\
\text { and ADL performance while also providing pain } \\
\text { relief at } 24 \text { mo follow-up in patients with MIRCT. }\end{array}$ \\
\hline Ruiz Ibán et al., $2018^{45}$ & $\begin{array}{l}\text { Constant score, Quick Dash; } \\
\text { flexion, external rotation, } \\
\text { internal rotation, abduction, } \\
\text { simple shoulder score }\end{array}$ & Median 24 & $\begin{array}{l}1 \text { patient lost to follow-up due to severe worsening } \\
\text { of Parkinson disease }\end{array}$ & $\begin{array}{l}\text { The use of the subacromial spacer does not seem to } \\
\text { be a reasonable alternative to the management of } \\
\text { the majority of patients with irreparable RTC } \\
\text { tears because only } 40 \% \text { of the patients in this } \\
\text { study experienced an improved Constant score at } \\
24 \text { mo. }\end{array}$ \\
\hline Senekovic et al., $2017^{46}$ & $\begin{array}{l}\text { Constant score, range of } \\
\text { motion, subjective pain } \\
\text { score, relief of shoulder } \\
\text { night pain, ultrasound } \\
\text { evaluation }\end{array}$ & 60 & \multirow[t]{2}{*}{$\begin{array}{l}\text { Dropout rate was } 9 / 24(37.5 \%) \text { w/ } 1 \text { patient } \\
\text { withdrawing at } 6 \text { weeks due to lack of } \\
\text { improvement, } 2 \text { patients died due to non-ortho } \\
\text { issues, } 1 \text { patient had RTSA at } 4 \text { years, and } 5 \text { other } \\
\text { patients refused to come for follow-up } \\
\quad-\end{array}$} & $\begin{array}{l}\text { Implantation of the InSpace system in patients with } \\
\text { MRCT refractory to conservative treatment is an } \\
\text { effective alternative because it results in } \\
\text { sustained improvement of total Constant score } \\
\text { through } 5 \text { y of follow-up. }\end{array}$ \\
\hline Yallapragada et al., $2018^{47}$ & $\begin{array}{l}\text { Constant score, Oxford } \\
\text { Shoulder Score; flexion, } \\
\text { abduction, external rotation }\end{array}$ & 12.6 & & $\begin{array}{l}\text { Implantation of a subacromial spacer or irreparable } \\
\text { RCTs results in significantly improved mean } \\
\text { Constant score, Oxford Shoulder Score, and } \\
\text { range of motion through a mean of } 12.6 \text { mo } \\
\text { follow-up. }\end{array}$ \\
\hline
\end{tabular}

of the Arm, Shoulder, and Hand score; RCT, rotator cuff tears; RTC, rotator cuff; RTSA, reverse total shoulder arthroplasty; SD, standard deviation; VAS, visual analog scale. 
Table 5. Baseline Demographics From Each Clinical Study Included in This Systematic Review

\begin{tabular}{|c|c|c|c|c|c|c|}
\hline Study & Age, $y$, mean $\pm S D$ & $\operatorname{Sex}(M: F)$ & Rotator Cuff Tear Size & Goutallier Stage & Patte Stage & Hamada Stage \\
\hline Basat et al., $2017^{26}$ & $64.3 \pm 3.55$ & $8: 4$ & $>5 \mathrm{~cm}(12)$ & Stage $4(12 / 12)$ & Stage $3(12 / 12)$ & - \\
\hline Deranlot et al., $2017^{38}$ & $69.8 \pm 7.9$ & $15: 22$ & - & $\begin{array}{l}\text { Stage } 2(2 / 38) \\
\text { Stage } 3(26 / 38) \\
\text { Stage } 4(10 / 38)\end{array}$ & $\begin{array}{l}\text { Stage } 2(1 / 38) \\
\text { Stage } 3(37 / 38)\end{array}$ & $\begin{aligned} \text { Stage } 1 & (24 / 38) \\
\text { Stage } 2 & (6 / 38) \\
\text { Stage } 5 & (1 / 38)\end{aligned}$ \\
\hline Gervasi et al., $2016^{7}$ & $74 \pm 6$ & $7: 8$ & - & $\begin{array}{l}\text { Stage } 3(6 / 15) \\
\text { Stage } 4(9 / 15)\end{array}$ & - & - \\
\hline Holschen et al., $2017^{39}$ & 62.4 & $6: 6$ & - & - & Stage $3(12 / 12)$ & - \\
\hline Malahias et al., $2019^{40}$ & $65.2 \pm 8.5$ & $18: 13$ & - & $\begin{array}{l}\text { Stage } \leq 2(22 / 31) \\
\text { Stage }>2(9 / 31)\end{array}$ & - & - \\
\hline Maman et al., $2018^{25}$ & - & - & - & - & - & - \\
\hline Naggar $2018^{41}$ & 69.3 & $13: 8$ & - & - & - & - \\
\hline Piekaar et al., $2020^{42}$ & 65 & $20: 19$ & - & - & - & - \\
\hline Prat et al., $2018^{43}$ & $70 \pm 7.9$ & $12: 12$ & - & - & - & - \\
\hline Ricci et al., $2017^{44}$ & 65.7 & $13: 17$ & - & - & - & - \\
\hline Ruiz Ibán et al., $2018^{45}$ & $69.4 \pm 7.5$ & $4: 11$ & $>3 \mathrm{~cm} \mathrm{(15)}$ & Stage $3(15 / 15)$ & - & - \\
\hline Senekovic et al., $2017^{46}$ & 68.8 & $12: 12$ & - & & - & - \\
\hline Yallapragada et al., $2018^{47}$ & 76.2 & $10: 4$ & - & Stage $\geq 3(14 / 14)$ & Stage $>2(12 / 14)$ & Stage $\geq 3(0 / 14)$ \\
\hline
\end{tabular}

F, female; M, male; SD, standard deviation.

Malahias et al. ${ }^{40}$ also demonstrated significant improvement in VAS score at rest, at night, and during activity following both partial rotator cuff repair with implantation of the balloon spacer and implantation of balloon spacer alone, with no significant difference in VAS scores between intervention groups. The UCLA shoulder score was also improved from $10.9 \pm 3.24$ preoperatively to $15.9 \pm 6.87$ postoperatively $(P=.001)$ in the study by Prat et al. ${ }^{43}$

\section{Shoulder ROM}

There was significant improvement of shoulder abduction (preoperative range: $70-113^{\circ}$; postoperative range: $110-165^{\circ}$ ), shoulder flexion (preoperative range: $80-130^{\circ}$; postoperative range: $106.5-161^{\circ}$ ), and external rotation (preoperative range: $25-44.5^{\circ}$; postoperative range: $35-63.7^{\circ}$ ) from preoperative to postoperative ROM after placement of the subacromial balloon spacer (Fig 7, A-C). In addition, Ricci et al. demonstrated positive results in ROM scores in the 3- (33-40.75, $P=.0002)$, 6- (30-43.56, $P=.0001), 12-(32.5-44.75$, $P<.0001)$, and 24-month (32.4-45.6, $P<.0001)$ follow-up groups. Senekovic et al. ${ }^{46}$ also demonstrated a mean change of ROM of $8.31 \pm 9.62^{\circ}(P<.0001)$ from baseline out to 60 months of follow-up.

\section{Biomechanics}

We were able to combine the data from 3 studies including 30 cadavers to demonstrate that in irreparable rotator cuff tears, subacromial balloon spacer placement resists superior humeral head migration by an average of $4.04 \mathrm{~mm}$ when the spacer is filled with $25 \mathrm{~mL}$ of saline and the shoulder is at 0 degrees of abduction without a load (confidence interval -6.09 to $-2.00 ; P=.0001$; Fig 8). ${ }^{48-50}$ Chevalier et al. ${ }^{51}$ also performed a study with 6 cadaveric shoulders to determine the effect of placing a subacromial balloon spacer on top of a supraspinatus tendon repair on the mean and peak subacromial pressure. They determined that the peak, or maximal subacromial pressure, during shoulder ROM (flexion-extension and abduction-adduction) was significantly decreased compared to repair without the overlying balloon spacer (1749.6 $\pm 80.7 \mathrm{MPa}$ vs 535.1 $\pm 27.6 \mathrm{MPa}, P<.0001$ for adduction-abduction and $1171.3 \pm 99.5 \mathrm{MPa}$ vs $468.7 \pm 16.0 \mathrm{MPa}, P<.0001$ for flexion-extension). Furthermore, the duration of time that the subacromial pressure was at peak pressure during ROM was reduced with the placement of the subacromial balloon spacer compared to without the balloon spacer. ${ }^{51}$ In addition, during shoulder adduction-abduction, the mean subacromial pressure over a repaired supraspinatus

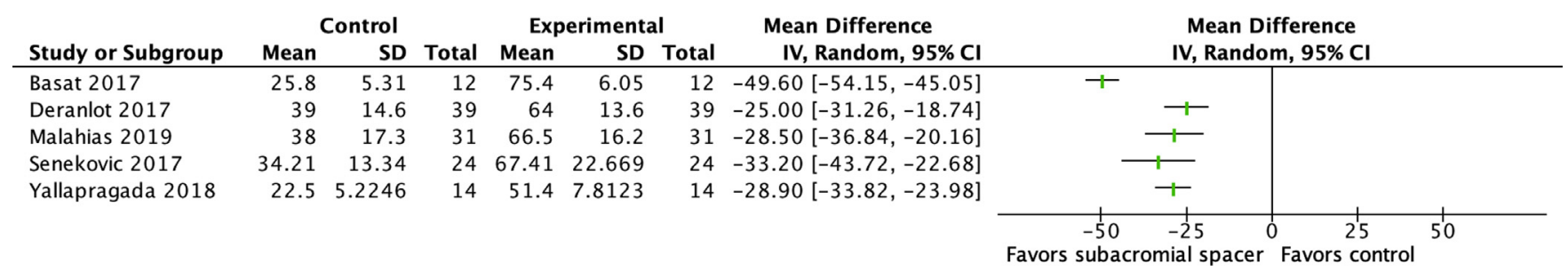

Fig 3. Forest plot comparing preoperative to postoperative Total Constant Score (TCS) values after placement of subacromial balloon spacer for patients with massive irreparable rotator cuff tear. (CI, confidence interval; SD, standard deviation.) 


\section{Mean Total Constant Score (TCS)}

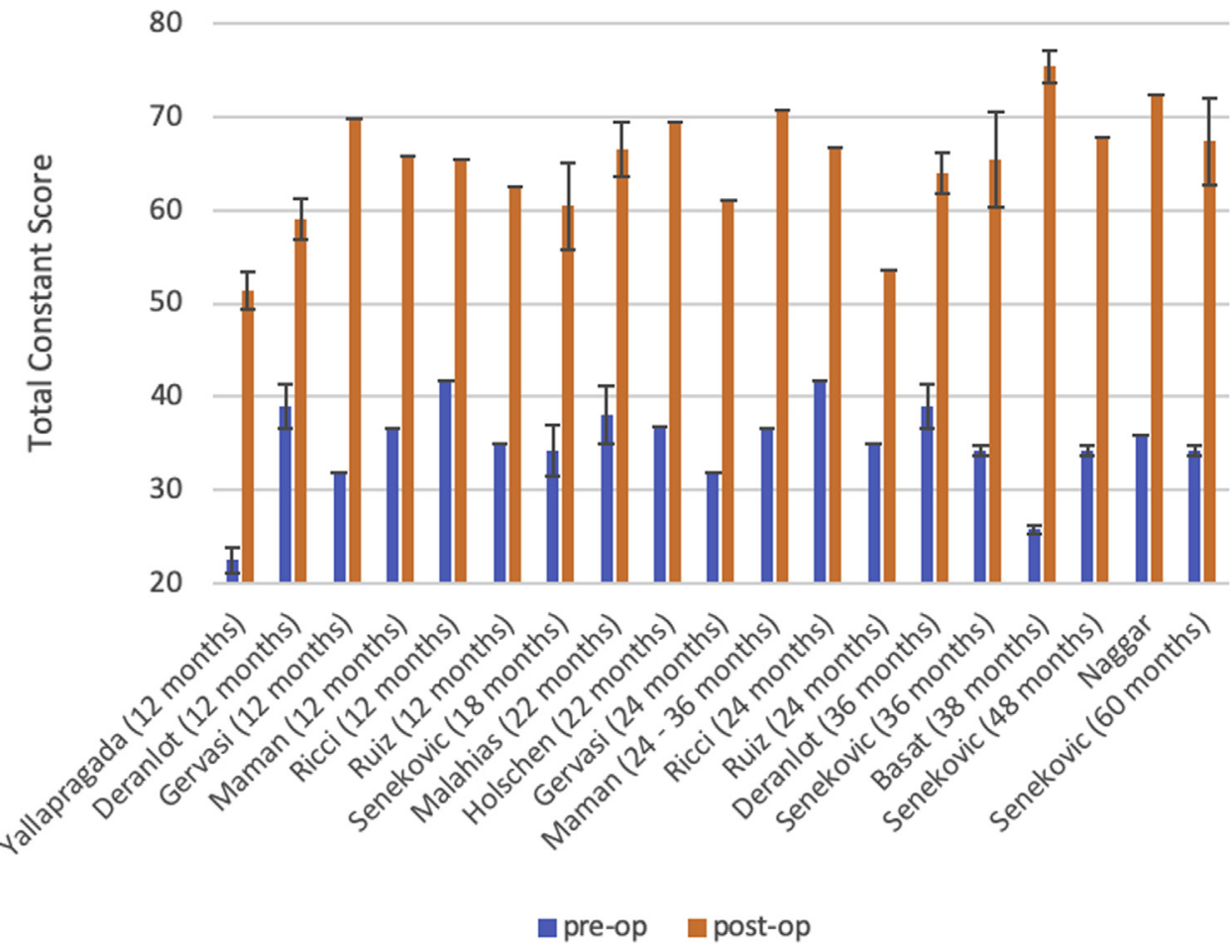

Fig 4. Comparison of mean preoperative to postoperative Total Constant Scores (TCS) after placement of subacromial balloon spacer. Author (length of followup). tendon was lower with an overlying subacromial balloon spacer compared with without $(121.7 \pm 9.5 \mathrm{MPa}$ vs $51.5 \pm 1.2 \mathrm{MPa}, P<.0001){ }^{51}$

\section{Radiographic Results}

In the study performed by Deranlot et al., ${ }^{38}$ the mean preoperative acromiohumeral distance in 38 shoulders was $8.2 \pm 3.4 \mathrm{~mm}$ whereas the mean acromiohumeral distance at an average of 32.8 months postoperatively was $6.2 \pm 3.1 \mathrm{~mm}$. In the study performed by Ricci et al., ${ }^{44}$ the mean preoperative acromiohumeral distance varied from 6.45 to $6.67 \mathrm{~mm}$ among 30 patients. However, in contrast to the study by Deranlot et al., ${ }^{38}$ the mean postoperative acromiohumeral distance was greater than the preoperative value for the 3 months (7.99 mm, $P<.0001), 6$ months $(8.16 \mathrm{~mm}, P<.0004)$, 12 months $(7.09 \mathrm{~mm}, P<.00067)$, and 24 months (7.94 mm, $P<.0007)$ follow-up groups. ${ }^{41}$ Prat et al. ${ }^{43}$ also evaluated the effect of the subacromial balloon spacers on acromiohumeral distance by comparing preoperative to 3-month postoperative upward migration indexes (UMIs) in 24 shoulders. In contrast to the results found by Ricci et al., Prat et al. ${ }^{43}$ determined no difference in humeral migration with the use of subacromial balloon spacers. In their study, the mean preoperative UMI was 1.15 (range 1.0-1.33) and the mean postoperative UMI was similarly at 1.16 (range 1.0-1.33). ${ }^{43}$ Deranlot et al. ${ }^{38}$ also evaluated the effect of subacromial balloon spacers on the progression of rotator cuff arthropathy. The authors report that among the 38 shoulders they studied, preoperatively, 7 shoulders had no evidence of rotator cuff arthropathy, 24 shoulders were Hamada stage 1, 6 shoulders were classified as Hamada stage 2, and 1 shoulder was Hamada stage 5. However, after management of the irreparable rotator cuff tears with a subacromial balloon spacer, progression of rotator cuff arthropathy was evident in 5 of the shoulders studied (4 patients

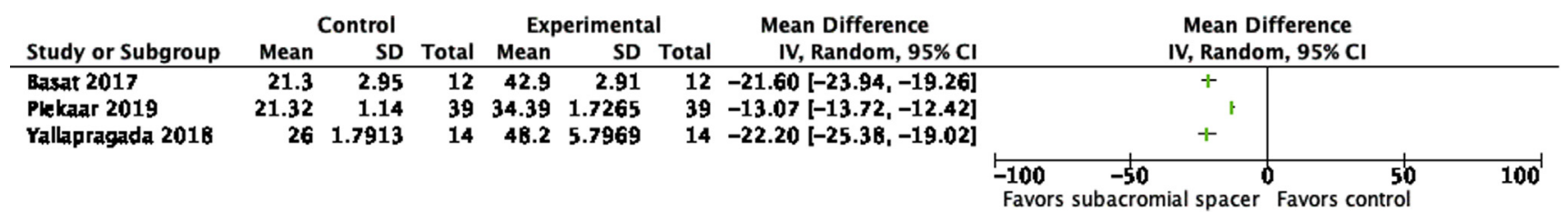

Fig 5. Forest plots comparing preoperative to postoperative Oxford Shoulder Score (OSS) after placement of subacromial balloon spacer for patients with massive irreparable rotator cuff tear 
Mean American Shoulder and Elbow Surgeons (ASES) Shoulder Score

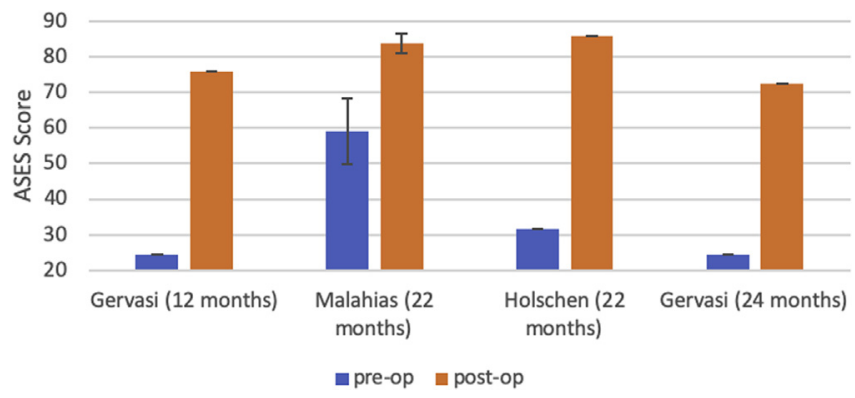

Fig 6. Comparison of mean preoperative to postoperative American Shoulder and Elbow Surgeons (ASES) Shoulder Score after placement of subacromial balloon spacer. Author (length of follow-up).

progressed by 1 Hamada stage and 1 patient progressed by 3 Hamada stages). ${ }^{38}$

\section{Time and Utility of Operation}

Ruiz Ibán et al. ${ }^{45}$ reported a median operative duration of 27.3 minutes. A study by Basat et al. ${ }^{26}$ reported a mean total operative duration of 33 minutes. Two other studies reported a mean of 10 minutes for balloon spacer implantation, with a range from 2 to 20 minutes, and a decrease in time to implantation as the surgeon gained more experience with the procedure., ${ }^{7,46}$

\section{Cost Analysis}

In an estimate of costs during a 24-month follow-up period, Castagna et al. ${ }^{52}$ demonstrated that use of a subacromial balloon spacer was less costly, more effective, and therefore associated with increased QALYs for patients with irreparable rotator cuff tears in comparison with arthroscopic partial repair and shoulder arthroplasty. Mean total per patient cost of the InSpace balloon spacer procedure was 17,327 euros in comparison with 31,031 euros for total reverse shoulder arthroplasty and 24,312 euros for arthroscopic partial rotator cuff repair. Although the subacromial balloon spacer was more costly than conservative management, it offers improvement in QALYs for a mean additional cost of 522 euros. The group concluded that the use of subacromial balloon spacer was the most cost-effective strategy for irreparable rotator cuff tears.

\section{Patient Satisfaction}

A total of 4 studies reported patient satisfaction scores following surgery in a combined 82 patients. ${ }^{7,39,40,43}$ A total of 13 of 15 patients rated their satisfaction from 8 to 10 on a 10 -point scale, with the value 10 representing "very satisfied." There was a mean of 3.7 on the 4-point Likert satisfaction scale, with most patients believing that the most invasive treatment option had been avoided (3.6). In a study by Malahias et al., ${ }^{40} 25$ of $31(80.6 \%)$ of patients were fully or almost satisfied
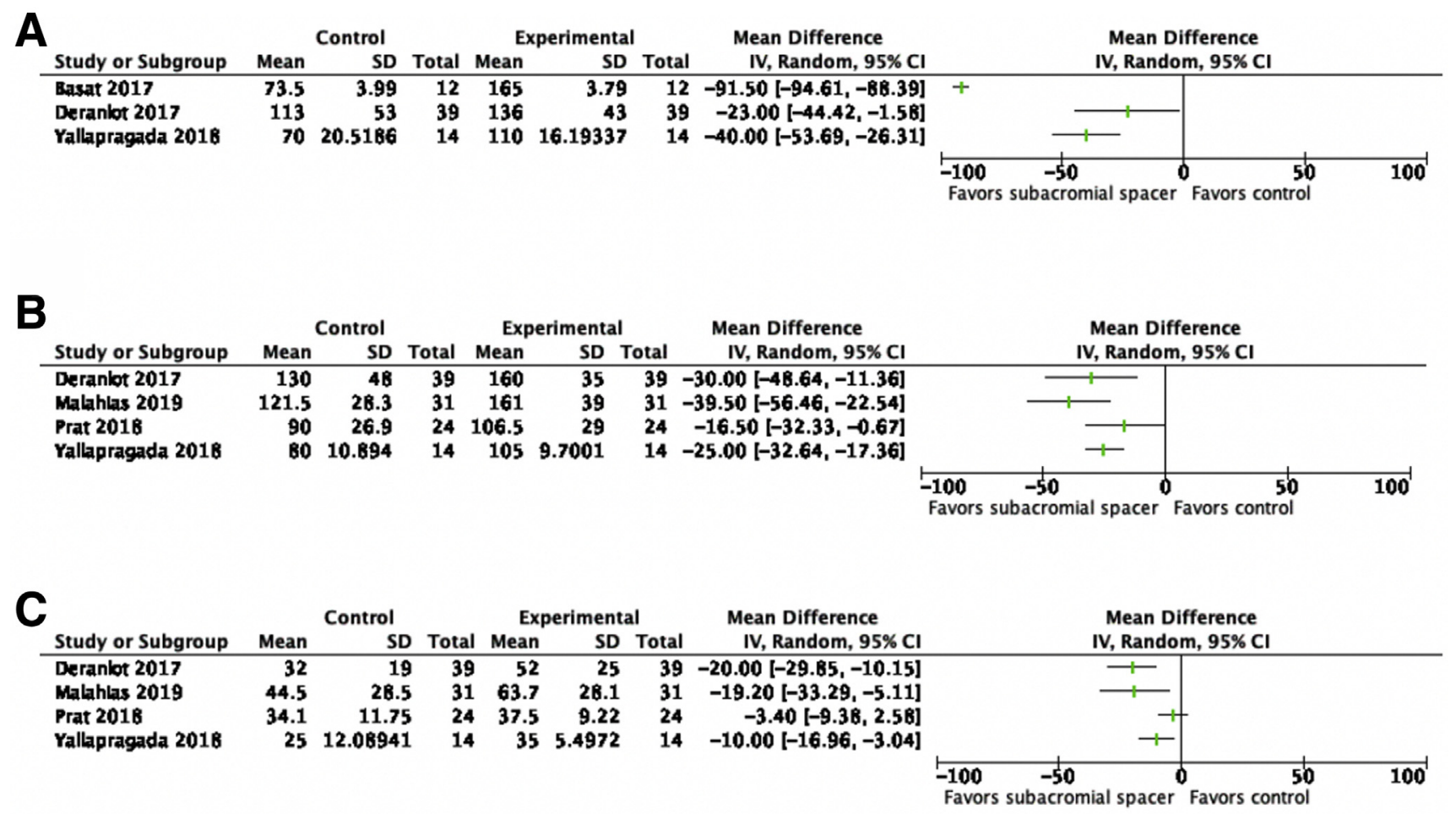

Fig 7. Forest plots comparing preoperative to postoperative shoulder range of motion (ROM) parameters (A, abduction, B, flexion, C, external rotation) after placement of subacromial balloon spacer for patients with massive irreparable rotator cuff tear. (CI, confidence interval; SD, standard deviation.) 


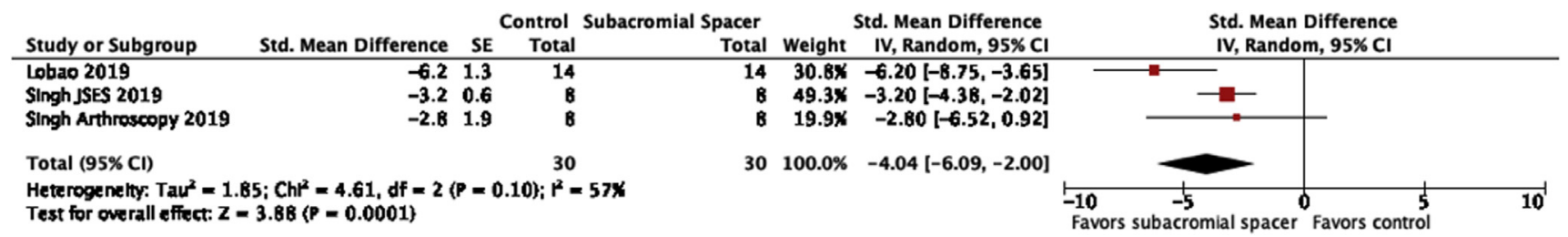

Fig 8. Forest plot comparing preoperative with postoperative values for humeral head position/resistance to superior translation of the humeral head. (CI, confidence interval; SD, standard deviation.)

with their balloon spacer treatment, whereas 3 of 31 $(9.6 \%)$ of patients reported moderate satisfaction, and 3 of $31(9.6 \%)$ reported no satisfaction. Prat et al. ${ }^{43}$ reported that $11 / 24(46 \%)$ of patients reported satisfaction with their treatment outcome.

\section{Complications}

In total, 1 of $350(0.29 \%)$ patients experienced a transient forearm dysesthesia in the lateral cutaneous nerve of the forearm after implantation of the subacromial balloon spacer. A total of 1 of $350(0.29 \%)$ procedures was complicated by superficial wound infection at the surgical site, which resolved after a course of antibiotics per orem, and 1 of $350(0.29 \%)$ procedures was complicated by a deep wound infection, which was culture-negative and treated with 1 week of intravenous antibiotics followed by 2 weeks of per orem antibiotics. One patient with an increasingly painful shoulder was found to have remnants of a deflated InSpace Balloon with transformation to scar tissue in the subacromial space on MRI. In total, 11 of 350 $(3.14 \%)$ of procedures required reoperation, including $5(1.42 \%)$ for InSpace Balloon migration, $1(0.29 \%)$ for synovitis, and $6(1.71 \%)$ underwent reverse total shoulder arthroplasty due to absence of clinical improvement or worsening of symptoms at various postoperative follow-up durations ranging from 6 weeks to 16 months. A total of 4 patients were found to have synovitis on MRI at 3 years postimplantation, and there was 1 shoulder dislocation at 6 weeks postoperative secondary to an acute trauma.

\section{Discussion}

Our study results demonstrate that the use of subacromial balloon spacers for the management of patients with irreparable rotator cuff tears results in a significant improvement in the following clinical outcome measures: TCS,, ,25,26,38,3,40,41,44,45,46,47,53 OSS, $^{26,42,47}$ and ROM parameters such as mean shoulder abduction, mean shoulder elevation, internal rotation, and external rotation. ${ }^{26,39,40,42,44,45}$ Furthermore, the clinical improvements in ASES, TCS, shoulder ROM, and patient satisfaction associated with subacromial balloon spacer use are comparable to those seen after management with other treatments for massive, irreparable rotator cuff tears such as subacromial debridement, ${ }^{54,55}$ biceps tenotomy, ${ }^{56}$ partial rotator cuff repair, ${ }^{57-59}$ latissimus dorsi transfer, ${ }^{60}$ and reverse total shoulder arthroplasty. ${ }^{14,15}$ In addition, the mean improvement of 33 points in TCS following placement of balloon spacer significantly exceeds the minimal clinically important difference threshold of 10.4 for TCS in patients with rotator cuff tears. ${ }^{61}$

The present findings are consistent with the systematic reviews by Moon et al. ${ }^{29}$ and Stewart et al., ${ }^{30}$ which demonstrated improvemet in ASES and TCS scores associated with subacromial spacer use for the treatment of massive, irreparable rotator cuff tears. However, this systematic review was the first of its kind to analyze all available data regarding biomechanical, clinical, and cost outcomes as well as complications associated with subacromial balloon spacer use for the surgical management of massive, irreparable rotator cuff tears. Therefore, with this present systematic review, we are able to demonstrate that the use of subacromial balloon spacers for the management of massive, irreparable rotator cuff tears results in the improvement of shoulder function scores, shoulder ROM testing, QALYs, and both kinematic and kinetic biomechanical measures, all with minimal complications.

It is worth noting that a majority of these studies included interventions featuring subacromial balloon implantation in addition to biceps tenotomy and $9.43 \%$ $(33 / 350)$ were performed in conjunction with partial rotator cuff repair; therefore, the true effect of subacromial balloon spacer use alone is not fully elucidated. Maman et $a .^{25}$ attempted to answer this question, as their study demonstrated no difference in functional outcomes such as TCS following placement of the balloon spacer both with and without biceps tenotomy and Senekovic et al. ${ }^{46}$ corroborated these findings in a group of 9 patients. Malahias et al. ${ }^{40}$ and Holschen et al. ${ }^{39}$ both demonstrated that balloon spacer implantation with concomitant partial rotator cuff repair provided no significant improvement in clinical outcomes compared to balloon spacer placement alone. In addition, Gervasi et al. $^{7}$ and Maman et al. ${ }^{25}$ performed the balloon spacer implantation procedure simply under fluoroscopic guidance with local anesthesia. While such an approach may result in the missed opportunity to treat additional pathologies such as bursitis and biceps tendinitis, ${ }^{39}$ the potential for decreased anesthesia requirement and reduced operative time $e^{7,25,41}$ 
makes the subacromial balloon spacer a less-invasive but equally effective option for the surgical management of massive, irreparable rotator cuff tears.

The reasons for the clinical improvements with the subacromial balloon spacer demonstrated in this study are multifactorial. We were able to determine that placement of a subacromial balloon spacer is able to effectively resist superior humeral head migration. ${ }^{48-50}$ Several biomechanical studies are able to demonstrate that in the cadaveric shoulder, the humeral head may superiorly translate from 3.5 to $4.2 \mathrm{~mm}$ at 0 degrees of abduction after a massive rotator cuff tear. ${ }^{48,50}$ Biomechanically, by superiorly translating the humeral head, the deltoid muscle, a muscle essential for shoulder ROM, is shortened. Therefore, by resisting superior humeral head migration, placement of a subacromial balloon spacer is able to restore both the native glenohumeral joint position and the deltoid moment arm. This concomitant restoration of joint position and deltoid function may be the cause for the improved shoulder ROM and overall function associated with the placement of subacromial balloon spacer.

In addition, the placement of a subacromial balloon spacer has been demonstrated to increase glenohumeral contact pressure. In a cadaveric study, Lobao et al. ${ }^{48}$ 2019 demonstrated that the placement of a balloon spacer above a rotator cuff repair is associated with significantly increased glenohumeral contact pressure at 0,30 , and $60^{\circ}$ of abduction compared with repair alone. This result further supports the ability of the subacromial balloon spacer to restore native glenohumeral joint position and articulation. The subacromial balloon spacer is also effective in decreasing peak subacromial pressure. In a cadaveric study performed by Chevalier et al., ${ }^{51}$ the authors were able to demonstrate that the placement of a subacromial balloon spacer above a repaired supraspinatus tear decreased both the mean and peak subacromial pressure during passive ROM. Therefore, placement of the subacromial balloon spacer could theoretically be used to prevent retear of a primary rotator cuff repair by reducing subacromial impingement and injury to the repair during the rehabilitation process.

In addition to the clinical biomechanical benefits illustrated, this systematic review demonstrates a financial benefit with the use of subacromial balloon spacers for the management of patients with an irreparable rotator cuff tear. Castagna et al. ${ }^{52}$ concluded that the use of subacromial balloon spacers results in improved QALYs in comparison with conservative treatment and both arthroscopic partial rotator cuff tear and shoulder arthroplasty. This is the only study of its kind, and additional studies are required to validate the financial benefit of using subacromial balloon spacers for irreparable rotator cuff tears.

One potential limitation of the use of subacromial balloon spacers stems from the fact that it biodegrades.
The subacromial balloon spacer is made of poly(L-lactide-co- $\varepsilon$-caprolactone), which is a biodegradable material previously shown to degrade over a period of 12 months. ${ }^{62,63}$ Through ultrasonographic and MRI evaluation, one study found that the balloon spacer was barely detectable in about $50 \%$ of patients after 6 months and MRI in 19 patients confirmed total biodegradation of the device within 3 years. However, despite degradation of the device, implantation of the balloon appears to have lasting effects on shoulder pain and function scores even after 5-year follow-up. ${ }^{46}$ Although the exact mechanism for persistent relief beyond device degradation has not yet been fully elucidated, it is possible that this benefit stems from adaptation of muscle forces due to restoration of the humeral head positioning or from a reduction in subacromial inflammatory conditions such as bursitis or synovitis due to the frictionless balloon surface while the balloon is intact. ${ }^{39}$

Like all implantable materials, there is a risk of local foreign body response and local irritation, infection, and inflammation with the subacromial balloon spacer. Poly(L-lactide-co- $\varepsilon$-caprolactone) is not known to have toxic properties, ${ }^{64}$ and review of the literature demonstrates very few complications associated with implantation of the subacromial balloon spacer in humans. ${ }^{1,7,26,38-40,42,45-48,5} 3$ A rodent study by Ramot et al. ${ }^{64}$ was notable for development of a fibrosarcoma at the subcutaneous implantation site of 1 rodent. In a 5 -year follow-up study, Senekovic et al. ${ }^{46}$ noted 2 patients with synovitis associated with slight deterioration in shoulder function after implantation; however, there was no baseline imaging for these patients, and it was not felt to be possible to determine if these were truly a device-related complication.

\section{Limitations}

The primary limitation of this study stems from the low quality of evidence of the included studies. The majority of included studies are retrospective and without a control group, which make it difficult to draw conclusions for clinical decision making in comparison to other surgical interventions considered for massive irreparable rotator cuff tears. Second, the methods for determination of an irreparable rotator cuff tear were heterogenous across included studies and largely relied on the interpretation of each individual surgeon, thus introducing observer bias. In 3 studies, funding was provided by Ortho-Space Inc., the manufacturer of the device under study. Furthermore, 2 biomechanical studies consisted of researchers who are employees or own stocks in the company. ${ }^{46,48,50,65}$ In addition, the length of follow-up of several studies was limited, which precludes the comparison of long-term clinical and cost-effectiveness between balloon spacers and other surgical interventions for massive irreparable 
rotator cuff tears. Furthermore, generalizability of study findings and study power are limited based on the small sample size in each study. Eleven of the studies included subacromial decompression and/or biceps tenotomy in addition to implantation of a subacromial balloon spacer, making it difficult to decipher which of these interventions was most responsible for the reported clinical outcomes. Finally, the clinical and radiographic data assessment was performed across multiple institutions and examiners, thereby introducing the potential for a measurement bias. However, the reliability of these measurements was improved through the use of validated assessment tools.

\section{Conclusions}

Existing literature of subacromial balloon spacers has high risk of bias, lack of appropriate control, and low level of evidence. A qualitative synthesis indicates that subacromial balloon spacer implantation in patients with massive irreparable rotator cuff tears is costeffective and leads to improved function (TCS and OSS) and ROM. In cadaveric studies, subacromial balloon spacers resisted superior humeral head migration and reduced subacromial pressure. The theoretical risk of biodegradation of the balloon spacer has not been substantiated in study of up to 5-year follow-up, and the risk of complications from this procedure appears to be minimal.

\section{Acknowledgment}

Our group would like to acknowledge and thank Mr. John W. Cyrus, Research and Education Librarian at Tompkins-McCaw Library for his contributions in development of the literature search strategy.

\section{References}

1. Piekaar RSM, Bouman ICE, van Kampen PM, van Eijk F, Huijsmans PE. Early promising outcome following arthroscopic implantation of the subacromial balloon spacer for treating massive rotator cuff tear. Musculoskelet Surg 2018;102:247-255.

2. Yamamoto A, Takagishi K, Osawa T, et al. Prevalence and risk factors of a rotator cuff tear in the general population. J Shoulder Elbow Surg 2010;19:116-120.

3. Greenspoon JA, Millett PJ, Moulton SG, Petri M. Irreparable rotator cuff tears: Restoring Joint kinematics by tendon transfers. Open Orthop J 2016;10:266-276.

4. Bedi A, Dines J, Warren RF, Dines DM. Massive tears of the rotator cuff. J Bone Joint Surg A 2010;92:1894-1908.

5. DeOrio JK, Cofield RH. Results of a second attempt at surgical repair of a failed initial rotator-cuff repair. J Bone Joint Surg Am 1984;66:563-567.

6. Gerber C, Fuchs B, Hodler J. The results of repair of massive tears of the rotator cuff. J Bone Joint Surg Am 2000;82:505-515.
7. Gervasi E, Maman E, Dekel A, Cautero E. Fluoroscopyguided biodegradable spacer implantation using local anesthesia: Safety and efficacy study in patients with massive rotator cuff tears. Musculoskelet Surg 2016;100:19-24.

8. Khair MM, Gulotta LV. Treatment of irreparable rotator cuff tears. Curr Rev Musculoskelet Med 2011;4:208-213.

9. Walch G, Edwards TB, Boulahia A, Nové-Josserand L, Neyton L, Szabo I. Arthroscopic tenotomy of the long head of the biceps in the treatment of rotator cuff tears: Clinical and radiographic results of 307 cases. J Shoulder Elbow Surg 2005;14:238-246.

10. Na Y, Zhu Y, Shi Y, et al. A meta-analysis comparing tenotomy or tenodesis for lesions of the long head of the biceps tendon with concomitant reparable rotator cuff tears. J Orthop Surg Res 2019;14:370.

11. Mura N, O’Driscoll SW, Zobitz ME, Heers G, An KN. Biomechanical effect of patch graft for large rotator cuff tears: A cadaver study. Clin Orthop Relat Res 2003;415: $131-138$.

12. Seker V, Hackett L, Lam PH, Murrell GAC. Evaluating the outcomes of rotator cuff repairs with polytetrafluoroethylene patches for massive and irreparable rotator cuff tears with a minimum 2-year follow-up. Am J Sports Med 2018;46:3155-3164.

13. Mihata T, Lee TQ, Watanabe $\mathrm{C}$, et al. Clinical results of arthroscopic superior capsule reconstruction for irreparable rotator cuff tears. Arthroscopy 2013;29:459-470.

14. Ernstbrunner L, Suter A, Catanzaro S, Rahm S, Gerber C. Reverse total shoulder arthroplasty for massive, irreparable rotator cuff tears before the age of 60 years: Longterm results. J Bone Joint Surg Am 2017;99:1721-1729.

15. Mulieri P, Dunning P, Klein S, Pupello D, Frankle M. Reverse shoulder arthroplasty for the treatment of irreparable rotator cuff tear without glenohumeral arthritis. J Bone Joint Surg Am 2010;92:2544-2556.

16. Zhang Q, Zhou J, Ge H, Cheng B. Tenotomy or tenodesis for long head biceps lesions in shoulders with reparable rotator cuff tears: A prospective randomised trial. Knee Surg Sport Traumatol Arthrosc 2015;23:464-469.

17. Ecklund KJ, Lee TQ, Tibone J, Gupta R. Rotator cuff tear arthropathy. J Am Acad Orthop Surg 2007;15:340-349.

18. Flurin P-H, Landreau P. Réparation arthroscopique des ruptures transfixiantes de la coiffe. Rev Chir Orthop Reparatrice Appar Mot 2005;91:31-39.

19. Favard L, Berhouet J, Colmar M, et al. Massive rotator cuff tears in patients younger than 65 years. What treatment options are available? Orthop Traumatol Surg Res 2009;95:19-26 (suppl 4).

20. Elhassan B, Christensen TJ, Wagner ER. Feasibility of latissimus and teres major transfer to reconstruct irreparable subscapularis tendon tear: An anatomic study. J Shoulder Elbow Surg 2015;24:e102-e103.

21. Memon M, Kay J, Quick E, et al. Arthroscopic-assisted latissimus dorsi tendon transfer for massive rotator cuff tears: A systematic review. Orthop J Sport Med 2018;6: 2325967118777735 .

22. Bond L, Clamp PJ, Gray K, Van Dam V. Patients' perceptions of doctors' clothing: Should we really be bare below the elbow? J Laryngol Otol 2010;124:963-966.

23. Mihata T, Bui $\mathrm{CNH}$, Akeda $\mathrm{M}$, et al. A biomechanical cadaveric study comparing superior capsule reconstruction 
using fascia lata allograft with human dermal allograft for irreparable rotator cuff tear. J Shoulder Elbow Surg 2017;26: 2158-2166.

24. Savarese E, Romeo R. New solution for massive, irreparable rotator cuff tears: The subacromial "biodegradable spacer." Arthrosc Tech 2012; 1:e69-e74.

25. Maman E, Safran O, Beyth S, et al. Biceps tenotomy does not affect the functional outcomes of patients treated with spacer implantation due to massive irreparable rotator cuff tears. Open Orthop J 2018;11:1577-1584.

26. Basat H, Kirçil C, Armangil M, Demirtş M. Treatment alternative for irreparable rotator cuff ruptures: Arthroscopic biodegradable balloon. Niger J Clin Pract 2017;20:952-957.

27. Mosher ZA, Ewing MA, Collins CS, et al. Usage trends of patient-reported outcome measures in shoulder literature [published online October 24, 2019]. J Am Acad Orthop Surg. https://doi.org/10.5435/jaaos-d-19-00455.

28. Angst F, Schwyzer HK, Aeschlimann A, Simmen BR, Goldhahn J. Measures of adult shoulder function: Disabilities of the Arm, Shoulder, and Hand Questionnaire (DASH) and Its Short Version (QuickDASH), Shoulder Pain and Disability Index (SPADI), American Shoulder and Elbow Surgeons (ASES) Society Standardized Shoulder Assessment Form, Constant (Murley) Score (CS), Simple Shoulder Test (SST), Oxford Shoulder Score (OSS), Shoulder Disability Questionnaire. Arthritis Care Res 2011;63:S174-S188 (suppl 11).

29. Moon AS, Patel HA, Ithurburn MP, Brabston EW, Ponce BA, Momaya AM. Subacromial spacer implantation for the treatment of massive irreparable rotator cuff tears: A systematic review. Arthroscopy 2019;35:607-614.

30. Stewart RK, Kaplin L, Parada SA, Graves BR, Verma NN, Waterman BR. Outcomes of subacromial balloon spacer implantation for massive and irreparable rotator cuff tears: A systematic review. Orthop J Sport Med 2019;7: 2325967119875717.

31. Stovold E, Beecher D, Foxlee R, Noel-Storr A. Study flow diagrams in Cochrane systematic review updates: An adapted PRISMA flow diagram. Syst Rev 2014;3.

32. Higgins JP, Green S. Cochrane Handbook for systematic reviews of interventions: Cochrane book series. New York: John Wiley \& Sons, 2008.

33. Slim K, Nini E, Forestier D, Kwiatkowski F, Panis Y, Chipponi J. Methodological index for non-randomized studies (Minors): Development and validation of a new instrument. ANZ J Surg 2003;73:712-716.

34. Randolph JJ. Online Kappa Calculator [Computer software]. Internet source. http://justusrandolph.net/kappa/. Accessed December, 18, 2019.

35. Cohen J. A coefficient of agreement for nominal scales. Educ Psychol Meas 1960;20:37-46.

36. McHugh ML. Interrater reliability: The kappa statistic. Biochem Medica 2012;22:276-282.

37. Gardner B, Simpson PM. Statistical methods in cancer research Lyon: International Agency for Research on Cancer, 2001;78, 2001.

38. Deranlot J, Herisson O, Nourissat G, et al. Arthroscopic subacromial spacer implantation in patients with massive irreparable rotator cuff tears: Clinical and radiographic results of 39 retrospectives cases. Arthroscopy 2017;33: 1639-1644.
39. Holschen M, Brand F, Agneskirchner JD. Implantation eines subakromialen Platzhalters bei Rotatorenmanschetten massenruptur: Klinisches Ergebnis arthroskopisch versorgter Patienten. Obere Extrem 2017;12:38-45.

40. Malahias MA, Brilakis E, Avramidis G, Antonogiannakis E. Satisfactory mid-term outcome of subacromial balloon spacer for the treatment of irreparable rotator cuff tears. Knee Surg Sport Traumatol Arthrosc 2019;27:3890-3896.

41. Naggar L. Massive irreparable rotator cuff tears without arthropathy: The role of the balloon (biodegradable spacer) and comparison with other operative treatments. Orthop Proc 2018;98-B:13.

42. Piekaar RSM, Bouman ICE, van Kampen PM, van Eijk F, Huijsmans PE. The subacromial balloon spacer for massive irreparable rotator cuff tears: Approximately 3 years of prospective follow-up. Musculoskelet Surg 2020;104:207-214.

43. Prat D, Tenenbaum S, Pritsch M, Oran A, Vogel G. Subacromial balloon spacer for irreparable rotator cuff tears: Is it an appropriate salvage procedure? J Orthop Surg $2018 ; 26(2)$.

44. Ricci M, Vecchini E, Micheloni GM, et al. A clinical and radiological study of biodegradable subacromial spacer in the treatment of massive irreparable rotator cuff tears. Acta Biomed 2017;88:75-80.

45. Ruiz Ibán MA, Lorente Moreno R, Ruiz Díaz R, et al. The absorbable subacromial spacer for irreparable posterosuperior cuff tears has inconsistent results. Knee Surg Sport Traumatol Arthrosc 2018;26:3848-3854.

46. Senekovic V, Poberaj B, Kovacic L, et al. The biodegradable spacer as a novel treatment modality for massive rotator cuff tears: A prospective study with 5-year followup. Arch Orthop Trauma Surg 2017;137:95-103.

47. Yallapragada RK, Apostolopoulos A, Katsougrakis I, Selvan TP. The use of a subacromial spacer-inspace balloon in managing patients with irreparable rotator cuff tears. J Orthop 2018;15:862-868.

48. Lobao MH, Canham RB, Melvani RT, Abboud JA, Parks BG, Murthi AM. Biomechanics of biodegradable subacromial balloon spacer for irreparable superior rotator cuff tears: Study of a cadaveric model. J Bone Joint Surg Am 2019:101.

49. Singh S, Reeves J, Langohr GDG, Johnson JA, Athwal GS. The subacromial balloon spacer versus superior capsular reconstruction in the treatment of irreparable rotator cuff tears: A biomechanical assessment. Arthroscopy 2019;35: 382-389.

50. Singh S, Reeves J, Langohr GDG, Johnson JA, Athwal GS. The effect of the subacromial balloon spacer on humeral head translation in the treatment of massive, irreparable rotator cuff tears: A biomechanical assessment. J Shoulder Elbow Surg 2019;28:1841-1847.

51. Chevalier Y, Pietschmann MF, Thorwächter C, et al. Biodegradable spacer reduces the subacromial pressure: A biomechanical cadaver study. Clin Biomech 2018;52:41-48.

52. Castagna A, Garofalo R, Maman E, Gray AC, Brooks EA. Comparative cost-effectiveness analysis of the subacromial spacer for irreparable and massive rotator cuff tears. Int Orthop 2019;43:395-403.

53. Senekovic V, Poberaj B, Kovacic L, Mikek M, Adar E, Dekel A. Prospective clinical study of a novel biodegradable sub-acromial spacer in treatment of massive irreparable 
rotator cuff tears. Eur J Orthop Surg Traumatol 2013;23: 311-316.

54. Liem D, Lengers N, Dedy N, Poetzl W, Steinbeck J, Marquardt B. Arthroscopic debridement of massive irreparable rotator cuff tears. Arthroscopy 2008;24:743-748.

55. König MA, Braunstein VA. Tendon repair leads to better long-term clinical outcome than debridement in massive rotator cuff tears. Open Orthop J 2017;1 1:546-553.

56. Boileau P, Baqué F, Valerio L, Ahrens P, Chuinard C, Trojani C. Isolated arthroscopic biceps tenotomy or tenodesis improves symptoms in patients with massive irreparable rotator cuff tears. J Bone Joint Surg Am 2007;89:747-757.

57. Kim SJ, Lee IS, Kim SH, Lee WY, Chun YM. Arthroscopic partial repair of irreparable large to massive rotator cuff tears. Arthroscopy 2012;28:761-768.

58. Chen KH, Chiang ER, Wang HY, Ma HL. Arthroscopic partial repair of irreparable rotator cuff tears: Factors related to greater degree of clinical improvement at 2 years of follow-up. Arthroscopy 2017;33:1949-1955.

59. Di Benedetto ED, Di Benedetto P, Fiocchi A, Beltrame A, Causero A. Partial repair in irreparable rotator cuff tear: Our experience in long-term follow-up. Acta Biomed 2017;88:69-74.
60. Birmingham PM, Neviaser RJ. Outcome of latissimus dorsi transfer as a salvage procedure for failed rotator cuff repair with loss of elevation. J Shoulder Elbow Surg 2008;17: 871-874.

61. Kukkonen J, Kauko T, Vahlberg T, Joukainen A, Äärimaa V. Investigating minimal clinically important difference for Constant score in patients undergoing rotator cuff surgery. J Shoulder Elbow Surg 2013;22:1650-1655.

62. Burks CA, Bundy K, Fotuhi P, Alt E. Characterization of 75:25 poly(1-lactide-CO- $\varepsilon$-caprolactone) thin films for the endoluminal delivery of adipose-derived stem cells to abdominal aortic aneurysms. Tissue Eng 2006;12: 2591-2600.

63. Levy Y, Paz A, Yosef R Ben, et al. Biodegradable inflatable balloon for reducing radiation adverse effects in prostate cancer. J Biomed Mater Res B Appl Biomater 2009;91: 855-867.

64. Ramot Y, Nyska A, Markovitz E, et al. Long-term local and systemic safety of poly(l -lactide-co-epsilon-caprolactone) after subcutaneous and intra-articular implantation in rats. Toxicol Pathol 2015;43:1127-1140.

65. Haim Zada M, Kumar A, Elmalak O, et al. Biodegradable implantable balloons: Mechanical stability under physiological conditions. J Mech Behav Biomed Mater 2019;100. 